\title{
انتتاهية العدد
}

\section{بقلم الاسناذ |لوكنور أبو السعود أهمد الفهراني رئيس مجلس الإ|رة وعميد الكلية}

\section{ب}

الحمد له الذي بذكره تطئن القلوب، وتتفرج الكروب، أنزل آخر كتبه

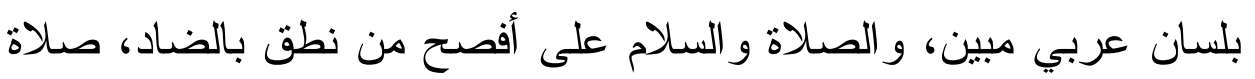

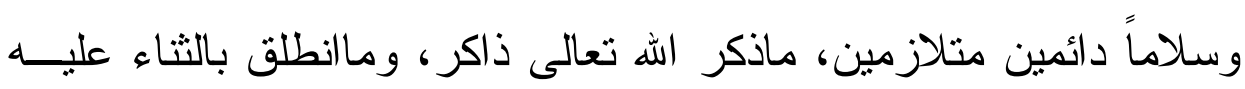

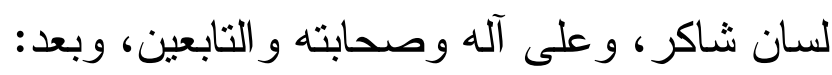
فهذا عدد جديد من أعداد مجلة كليتا الفتية، العدد السادس و العشرين، يحوي النثاط العلمي لأعضاء هيئة التدريس في المجالات الأدبية و البلاغية و النقدية و اللغوية.

فقي مجال الأدب و النقد قدم الدكتور / يوسف هممد نتحي عبد الوهاب

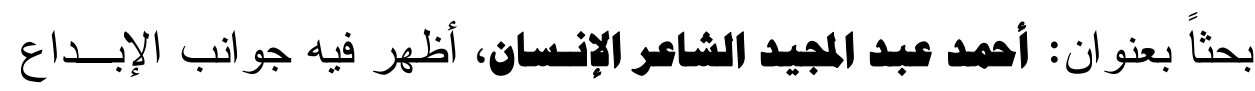

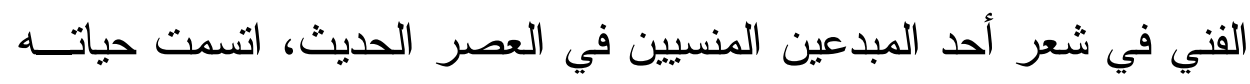
وشعره بالإنسانية العالية، مع جمع ما أمكن جمعه من نتاجه الثعائ الثعري.

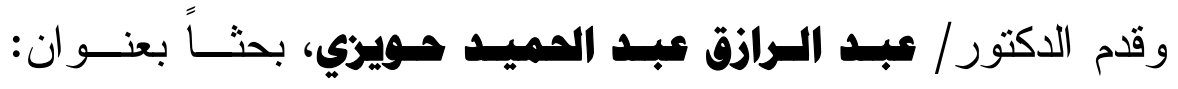

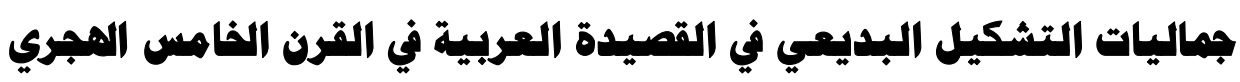

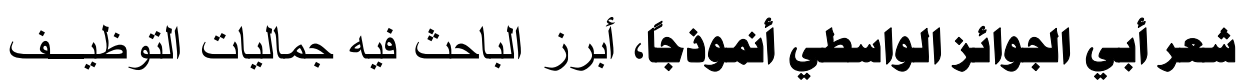


البديعي في شعر أبي الجو ائز الو اسطي من خلال ديو انـــهـ الـــي جمعـــ

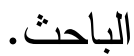

وقدم الدكتور / هممد هممد بظاظو، بحثًا بعنوان: فن التعزية النثريـة دراسة في المضمون والنسقق، عالج الباحث في در استه فن التعزية النثرية،

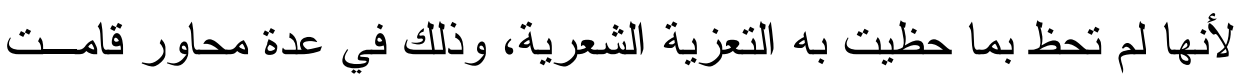

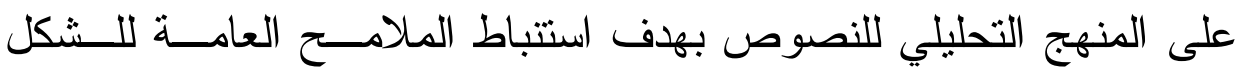
و المضمون في هذا الفن الأدبي.

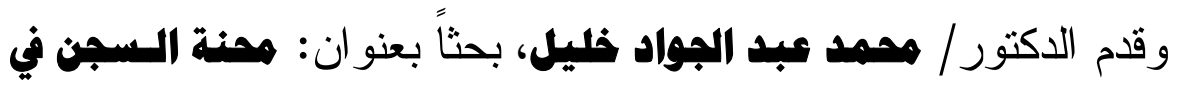

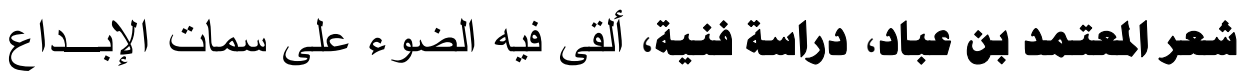
الفني في شعر الأسر و السجن الذي أبدعه المعتمد بن عباد في محنة سجنه التي صبغت شعره بالعو اطف الإنسانية المعبرة عن همومه و آلامه. وفي مجال أصول اللغة قدم الدكتور / هممود كمال سعد أبو العينين،

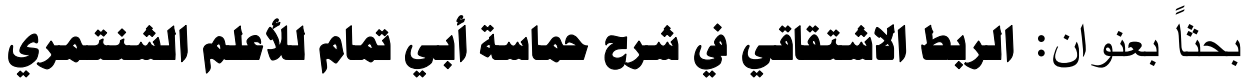

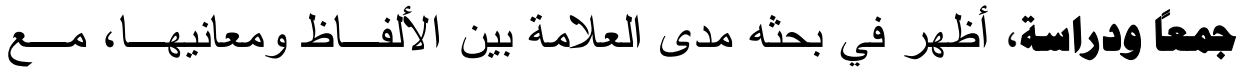
التعرف على جهود شر اح الثعر العربي الرصين في هذا الجانب المهم من جو انب در اسة اللغة.

وقدمت الدكتورة/ سوسسن هسانين أهمسد الهدهـد، بحثــاً بعنـــوان:

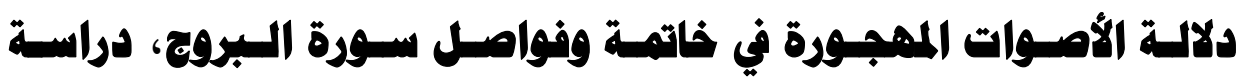

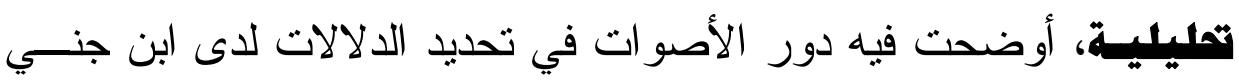
الذي أثنبت بعبقريته دور الأصو ات في تحديد دلالات الكلمات، وذللك مسنـ

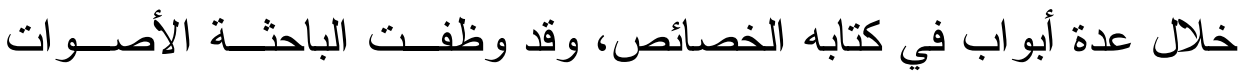
المجهورة الو اردة في خاتمة وفو اصل سورة البروج بمخارجها وصــفاتها $-V$ - 
في ضوء السياق في الدلالة على المعنى العام للآيات وعلى الجــو العــام للسورة و على المخاطبين.

وفي مجال البلاغة و النقد قدم الدكتور / رضا السعيد فايد، بحثًا بعنوان:

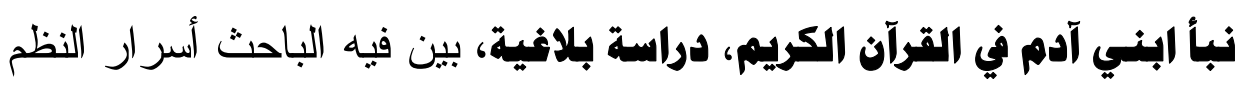

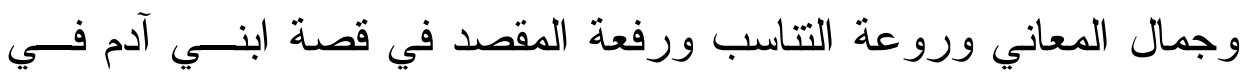

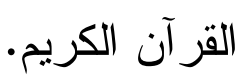

وقدم الدكتور / وليد إبراهيم همسودة، بحثًا بعنو ان: مواقف السدكتور:

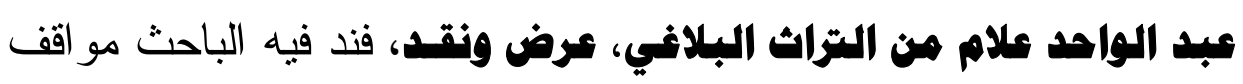

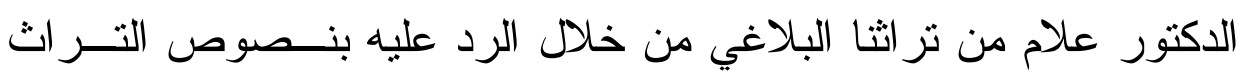

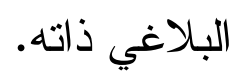

وقدم الدكتور / تاهر هممد أحمد حجازي، بحثاً بعنوان: الدلالة البلاغية

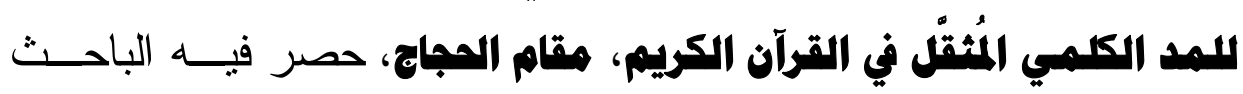

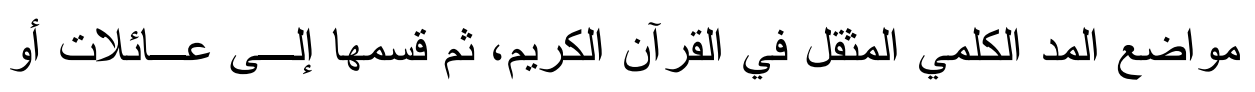

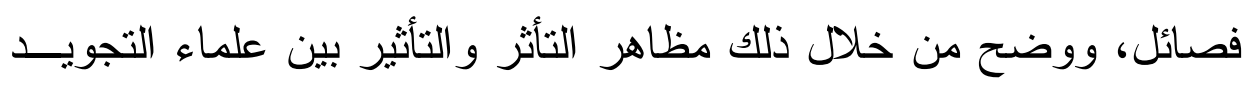
القر آني و الصوتيات و البلاغة.

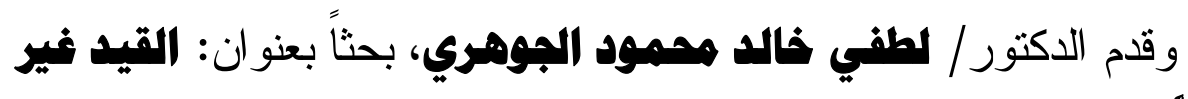

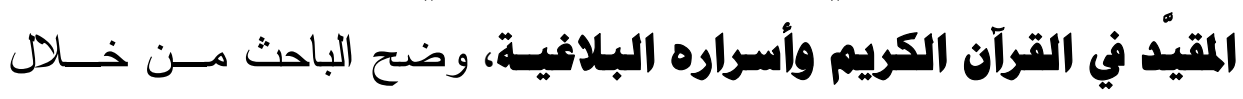
در استه الأغر اض البلاغية للقيد غير المقيد في القر آن الكريم.

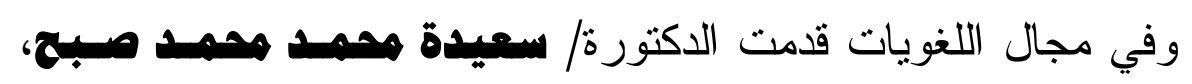
بحثاً بعنوان: أثر أمن البس أو خوفه في القاعدة اللغوية دراسة نهويسة

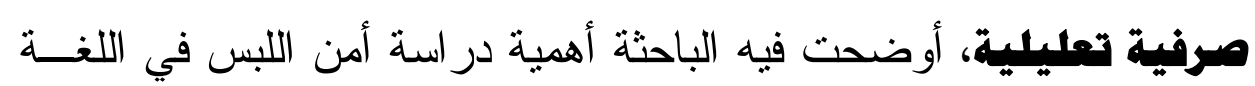
العربية ومدى تأثثيره على القو اعد النحوية و الصرفية. 


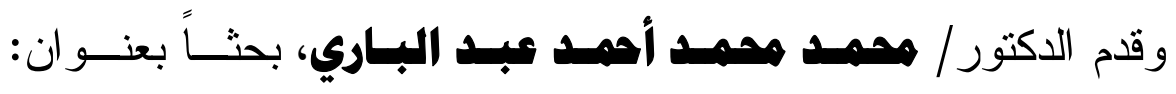
هخالفات الفراء النموية للإمام الكساني في ضود هماني القرآن الكريم

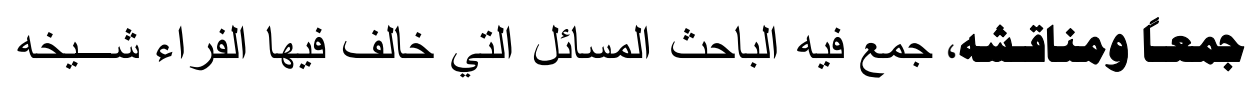

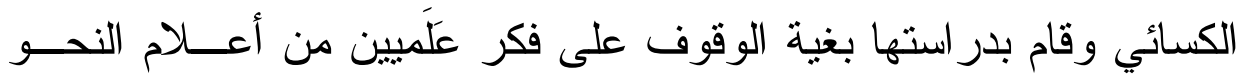
الكوفي.

كل هذه البحوث تثبت شغف أعضاء هيئة التذريس بالعربيــة ولـسـان

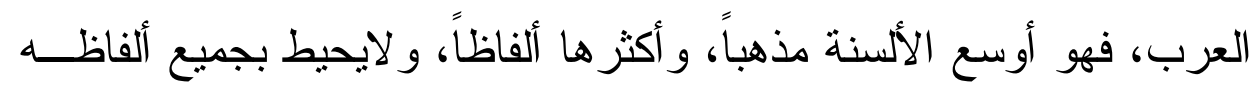
إنسان غير نبي كما قال علماؤنا.

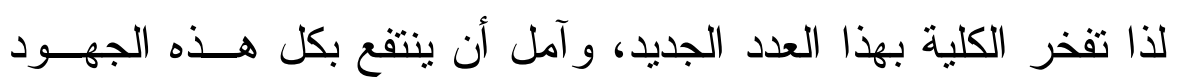
العلمية المباركة كل طلاب العلم في كل زمان ومكان.

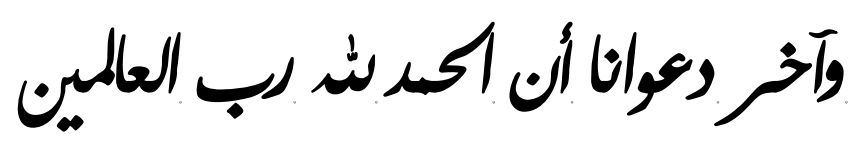

